\title{
EDUCAÇÃO PERMANENTE DE PROFESSORES: A REFFLEXÃO-AÇÃO NA PROMOÇÃO DA ALIMENTAÇÃO SAUDÁVEL NAS ESCOLAS
}

\author{
Continuing education of teachers: reflection-action in promoting \\ healthy eating in schools
}

\author{
Vera Lúcia Xavier Pinto ${ }^{1}$ \\ Lara Lima ${ }^{2}$ \\ Rachel Tellechea Inda ${ }^{3}$ \\ Michelle Medeiros ${ }^{4}$ \\ Ingrid Wilza Leal Bezerra ${ }^{5}$
}

\begin{abstract}
RESUMO
A escola é um espaço privilegiado para se trabalhar o conceito de alimentação saudável. Com a finalidade de contribuir para a realização de práticas pedagógicas relacionadas à temática "Alimentação e Nutrição" em uma comunidade pesqueira, foi ofertado aos professores da localidade o curso "Formação do Formador em Educação Nutricional". O objetivo deste trabalho foi refletir sobre a importância do curso como promotor do pensamento reflexivo e desencadeador de mudanças nas ações dos educadores participantes. A coleta de material se deu por meio da observação e dos registros dos escritos e enunciações elaborados pelos participantes. Foi realizada a análise de conteúdo e duas categorias emergiram: reflexão-ação na alimentação e reflexão-ação na prática pedagógica. Os resultados mostraram que a realização desse curso proporcionou aos professores a aquisição de novos conhecimentos em relação à alimentação saudável, propiciando alterações em suas vidas pessoal e profissional. Foi concluído que: 1) esses novos conhecimentos alimentaram, nos professores, o desejo de realizar mudanças na vida pessoal e de incluir em suas práticas pedagógicas o conceito de alimentação saudável; 2) o trabalho de formação permanente é importante e deve
\end{abstract}

\footnotetext{
${ }^{1}$ Professora do Departamento de Nutrição/CCS/UFRN. Doutora em Educação pelo Programa de pós graduação em Educação / UFRN. Mestre em Ciências Sociais. E-mail: verapintoufrn@hotmail.com

2 Pós graduanda em Nutrição Clínica (Universidade Estácio de Sá). Professora do Programa Nacional de Acesso ao Ensino Técnico e ao Emprego (Pronatec). Nutricionista Gerente de Unidade em GRSA.

${ }^{3}$ Licenciada em Letras -UFRN. Pedagoga Waldorf - Federação das Escolas Waldorf do Brasil -SP. Pesquisadora do Núcleo de Pesquisa de Ecologia Onírica - Instituto de EducaçãoFURG. Fundadora do Espaço Oniricum- Assessoria em Desenvolvimento de Potencialidades. 4 Doutora em Ciências Sociais (PPGCS/UFRN), onde também titulou-se como mestre. Graduada em Nutrição pela Universidade Federal do Rio Grande do Norte. Professora de Antropologia da Nutrição na Universidade Federal de Campina Grande, Campus Cuité, onde também é coordenadora do G.U.L.A. (Grupo Universalidades, Literatura e Alimentação), vinculado ao Núcleo PENSO (Núcleo de Pesquisa e Estudos em Nutrição e Saúde Coletiva). 5 Nutricionista. Professora do Departamento de Nutrição/CCS/UFRN. Doutoranda do Programa de pós graduação em administração - PPgA / UFRN. Linha de Pesquisa: Políticas e Gestão Públicas.
}

PINTO, Vera L. X. et al. Educação permanente de professores: a reflexão-ação na promoção da alimentação saudável nas escolas. Extensão em Foco, Curitiba: Editora da UFPR, nr.10, jul/dez 2014, p.37-58. ISSN 2358-7180. 
estender-se a toda comunidade escolar e à família para um apoio ao trabalho do professor; 3) a reflexão-ação é uma via importante para a formação de professores para o trabalho com a Promoção da Alimentação Saudável nas Escolas (PASE).

Palavras-chave: promoção da alimentação saudável nas escolas; pensamento reflexivo; educação alimentar e nutricional; educação permanente.

\begin{abstract}
The school is a privileged space to work with the concept of healthy eating. With the aim of contributing to the achievement of pedagogical practices related to the theme "Feeding and Nutrition" in a fishing community, the course "Training of Nutrition Education Educators" was offered to local teachers. The objective of this work was to reflect about the importance of the course as a promoter of reflective thinking and triggering changes in the actions of educators who participated. The sample collection was done through observation and the writings records and utterances produced by the participants. Content analysis was performed and two categories emerged: reflection-action in feeding and reflection-action in pedagogical practice. The results showed that this course provided acquisition of new knowledge in relation to healthy eating to teachers, promoting changes in their personal and professional lives. It was concluded that: 1) the new knowledge fed, in teachers, the desire to make changes in their personal lives and include in their pedagogical practices the concept of healthy eating; 2) the continuing education work is important and it should be extended to the whole school community and family to support the work of teachers; 3 ) the reflection-action is important for the teachers' training on working with the Healthy Eating at Schools Promotion - Promoção da Alimentação Saudável nas Escolas (PASE).
\end{abstract}

Keywords: healthy eating promotion at schools; reflexive thinking; eating and nutrition education; continuing education.

\title{
Introdução
}

A escola, por ser "[...] um espaço de ensino-aprendizagem, convivência e crescimento importante, no qual se adquirem valores fundamentais" (GONÇALVES, et. al, 2008, p. 182), torna-se, também, um local privilegiado para se trabalhar o conceito de alimentação saudável junto a crianças e adolescentes, por estes passarem ali parte do seu dia e nela construírem uma parcela significativa de sua identidade.

A importância desse ambiente como promotor de bons hábitos alimentares foi evidenciada no documento da Organização Mundial da Saúde (OMS) "Estratégia Global para Alimentação Saudável e Atividade Física” (BRASIL(a), 2004, p.43). Frente aos problemas enfrentados pelo setor saúde em um país como o Brasil, no qual doenças infecciosas e desnutrição coexistem com Doenças Crônicas Não Transmissíveis (DCNT)- tendo destaque o sobrepeso e a obesidade crescente entre crianças e adolescentes.

Sendo tais enfermidades preveníveis por opções aparentemente simples como a escolha por uma alimentação saudável, o não tabagismo e prática regular de

PINTO, Vera L. X. et al. Educação permanente de professores: a reflexão-ação na promoção da alimentação saudável nas escolas. Extensão em Foco, Curitiba: Editora da UFPR, nr.10, jul/dez 2014, p.37-58. ISSN 2358-7180. 
atividade física - tornou-se evidente o papel relevante da educação no combate a tais mazelas.

A necessidade dos setores saúde e educação trabalharem juntos levou à criação da portaria interministerial 1010 (BRASIL, 2006), que trata da Promoção da Alimentação Saudável nas Escolas, doravante nominada PASE.

Nesse documento, a educação alimentar e nutricional tem papel relevante. Seu Art. 3ำ traz como um dos eixos prioritários as "ações de educação alimentar e nutricional, considerando os hábitos alimentares como expressão de manifestações culturais regionais e nacionais".

O Art. $5^{\circ}$ versa sobre tais ações e apresenta a primeira delas como a necessidade de se "definir estratégias, em conjunto com a comunidade escolar, para favorecer escolhas saudáveis", e a última como a ambiciosa ideia de "incorporar o tema alimentação saudável no projeto político pedagógico da escola, perpassando todas as áreas de estudo e propiciando experiências no cotidiano das atividades escolares". (BRASIL, 2006).

Inspirado nessa portaria foi realizado um trabalho em uma comunidade pesqueira, a Reserva de Desenvolvimento Sustentável Estadual da Ponta do Tubarão (RDSEPT), na qual se desenvolviam atividades de extensão pelo Departamento de Nutrição da Universidade Federal do Rio Grande do Norte (UFRN), por meio do Programa "Em torno da mesa", financiado pelo programa "Petrobras fome zero".

Pescadoras da reserva estavam sendo formadas para elaborar preparações culinárias com o pescado local, ao mesmo tempo em que eram apoiadas na constituição de uma cooperativa, visando à comercialização de seus produtos no município e sua utilização na alimentação escolar.

A necessidade de ofertar aos estudantes um produto local que fosse efetivamente consumido por eles, levou à ideia de oferecer aos professores um curso sobre a alimentação e nutrição na infância e adolescência, apontando para uma compreensão dos aspectos biopsicossociais envolvidos na alimentação, para que juntos - pescadoras e professores - pudessem fomentar nos estudantes a opção por alimentos saudáveis.

O conceito de educação permanente, que norteou as atividades, foi o proposto por Cabello (2002), que a define como:

PINTO, Vera L. X. et al. Educação permanente de professores: a reflexão-ação na promoção da alimentação saudável nas escolas. Extensão em Foco, Curitiba: Editora da UFPR, nr.10, jul/dez 2014, p.37-58. ISSN 2358-7180. 
Um processo contínuo, que prossegue durante toda a vida, com o propósito de que toda pessoa possa manter-se atualizada a respeito das transformações populacionais, econômicas, políticas, tecnológicas, científicas, artísticas, socioculturais e ambientais de nosso mundo; alcançando o máximo desenvolvimento individual e social que lhe seja possível, e englobando todo tipo de experiências e atividades que sejam ou possam ser portadoras de educação. (CABELLO, 2002, p. 8586).

Sendo assim, a ideia do curso como uma oportunidade de aperfeiçoamento profissional foi abolida. A proposta foi criar condições para que os professores desenvolvessem o gosto pelo saber, apropriando-se desse para apoiar seus alunos na construção de uma comunidade mais saudável.

O paradigma reflexivo aliado ao pensamento complexo foi a opção metodológica. Como nos lembra Morin (2002, p. 91), lidar com a incerteza é algo que necessita ser aprendido e trabalhado nas escolas, e "[...] a resposta às incertezas da ação é constituída pela escolha refletida de uma decisão, a consciência da aposta, a elaboração de uma estratégia [...]".

Realizar tais ações requer a junção de razão e emoção. Segundo Alarcão (1996, p. 175), a reflexão é uma via para esse enlace, uma vez que se trata de "[...] um processo simultaneamente lógico e psicológico, combina a racionalidade da lógica investigativa com a racionalidade inerente à intuição e à paixão do sujeito pensante $[\ldots] "$.

Nós refletimos na ação e sobre ela, mas isso não nos torna reflexivos. A reflexividade "não é medida por discursos ou por intenções, mas pelo lugar, pela natureza e pelas consequências da reflexão no exercício cotidiano da profissão." (PERRENOUD, 2002, p.13).

A intenção do curso foi, portanto, "[...] recolocar o sujeito no lugar de destaque que lhe pertence quando desejar tornar-se um actor que se autonomize e que assume as suas responsabilidades nas aprendizagens e no horizonte que elas lhe abrem." (JOSSO, 1988, p. 49).

Assim, as autobiografias de formação (inclusive alimentar) foram tomadas como dispositivos desencadeadores de reflexividade, ou seja: os aspectos afetivos, cognitivos, culturais e situacionais emergentes nas narrativas autobiográficas foram

PINTO, Vera L. X. et al. Educação permanente de professores: a reflexão-ação na promoção da alimentação saudável nas escolas. Extensão em Foco, Curitiba: Editora da UFPR, nr.10, jul/dez 2014, p.37-58. ISSN 2358-7180. 
trabalhados na perspectiva da formação de um profissional capaz de compreender melhor tais manifestações na relação com o outro, favorecendo uma atitude de maior empatia com os sujeitos com os quais desenvolve um trabalho pedagógico, em especial com a temática da alimentação e nutrição.

Este texto é fruto das ponderações realizadas a partir das ações desenvolvidas junto aos professores. Seu objetivo é refletir sobre a importância do referido curso como promotor do pensamento reflexivo e desencadeador de mudanças nas ações dos educadores participantes.

\section{Procedimentos metodológicos}

Esta pesquisa trata das ações de formação desenvolvidas junto a professores, realizadas durante um ano, com encontros quinzenais, em 2007/2008. Foi formada uma turma em cada turno, oportunizando a todos os professores participarem, sem causar interferência ou prejuízo nas atividades das escolas.

Os colaboradores da pesquisa foram os 13 professores das escolas públicas e privadas de Educação Infantil e Ensino Fundamental situadas na RDSEPT, inscritos voluntariamente no curso.

A pesquisa foi submetida à aprovação pelo Comitê de Ética e Pesquisa da UFRN e os colaboradores assinaram o Termo de Consentimento Livre e Esclarecido (TCLE). Os nomes apresentados no texto são fictícios, inspirados em obras literárias.

O contato entre os pesquisadores e os professores foi direto, uma vez que as atividades de pesquisa e extensão aconteciam em paralelo. O corpus constou das fichas de inscrição, dos relatos orais escritos - realizados pelos professores durante o curso - e dos apontamentos feitos pelos pesquisadores em momentos de observação.

O curso foi pensado e realizado a partir de três eixos:

1) A compreensão de si e o despertar do sujeito reflexivo - cada professor foi incentivado a expor sua formação (inclusive alimentar). Esse olhar retrospectivo buscava vestígios dessa história em sua prática docente atual, não se limitando, portanto, à evocação do passado.

Propor que revissem suas histórias pessoais e que as socializassem tinha a intenção de que fosse construída uma percepção da história passada recente daquele

PINTO, Vera L. X. et al. Educação permanente de professores: a reflexão-ação na promoção da alimentação saudável nas escolas. Extensão em Foco, Curitiba: Editora da UFPR, nr.10, jul/dez 2014, p.37-58. ISSN 2358-7180. 
coletivo, para que emergisse a compreensão de que aspectos reverberavam ainda nas crianças e jovens daquela localidade.

Ao mesmo tempo, rever o presente servia como um estímulo para o desenvolvimento de uma visão prospectiva, passível de fundar ações inovadoras, novos projetos individuais e coletivos em função das oportunidades formativas vivenciadas.

A cada tema discutido, os professores realizavam esse exercício reflexivo, de pensar a criança e o adolescente que foram e o adulto que, aos poucos percebiam, estava sendo permanentemente construído em cada um.

2) A compreensão do outro - as crianças e adolescentes: quem são e o que necessitam

Nesse eixo foram discutidos os seguintes aspectos:

a) as ideias de vários autores em relação ao desenvolvimento cognitivo e afetivo da criança, como Piaget, Vigotski, Wallon e a abordagem da pedagogia Waldorf;

b) o crescimento e desenvolvimento físico da criança;

c) o cuidado com alimentação infantil sob a ótica da segurança alimentar e nutricional, desde o aleitamento materno até a pré adolescência;

d) a adolescência - o significado socioafetivo dessa fase da vida, e a construção da identidade;

e) o desenvolvimento físico na adolescência;

f) as necessidades nutricionais do adolescente e sua alimentação;

\section{3) O professor e a PASE: a efetivação de uma pedagogia nutritiva}

Neste eixo estavam inseridas:

a) a ideia da escola como promotora da alimentação saudável - a portaria 1010 e seus desafios;

b) alimentação e nutrição como conteúdo transdisciplinar;

c) a pedagogia de projetos como apoio à PASE;

d) produção de ferramentas pedagógicas para vivências com crianças a adolescentes da comunidade.

PINTO, Vera L. X. et al. Educação permanente de professores: a reflexão-ação na promoção da alimentação saudável nas escolas. Extensão em Foco, Curitiba: Editora da UFPR, nr.10, jul/dez 2014, p.37-58. ISSN 2358-7180. 
Dois momentos encerraram o curso com a utilização dos materiais produzidos pelos professores: a "Feira da criança", para a qual foram elaborados jogos, recitais, livros artesanais, brincadeiras e músicas para serem vivenciadas nesse momento junto a crianças de até 10 anos que estudavam na reserva; e o desfile de moda intitulado "A saúde está na moda", no qual os adolescentes junto com seus professores desfilaram com modelos criados para divulgar a ideia da alimentação saudável.

Durante todo o curso três elementos foram trabalhados intensamente:

1) A corporalidade: o início dos encontros era marcado pelo momento da roda rítmica e por brincadeiras que envolvem movimento, como "capitão mandou", para evidenciar a fragmentação corpo-mente que a escola produz.

2) A exaltação das atividades lúdicas: os jogos pedagógicos como ferramentas para a divulgação da alimentação saudável nas escolas foram incentivados, sendo apresentados modelos aos professores, que tiveram a oportunidade de vivenciar sua utilização, sendo motivados a construírem jogos similares, cujo tema girasse em torno da alimentação e nutrição.

3) O momento poético vivencial: todos os encontros terminavam com uma leitura prazerosa, uma fábula, um conto. Aqueles momentos eram mágicos e os adultos se entregavam ao deleite que todo ser humano desfruta ao ouvir uma bela história.

Foi aplicado ainda um check list para obter uma panorâmica sobre as condições físicas das cozinhas escolares e das práticas higiênico sanitárias nelas desempenhadas. Foi discutido com os professores o conceito de segurança alimentar e nutricional, as evidências de perigos encontradas na confecção dos alimentos para os estudantes.

Ao final do curso foi realizada uma avaliação, na qual os professores expressaram suas opiniões e sentimentos.

Os materiais que constituíam o corpus foram analisados em três fases, de acordo com a análise de conteúdo (BARDIN, 1977) como descrito a seguir:

a) Pré-análise: fase de realização do primeiro contato com o material feito através da leitura flutuante. Logo em seguida à inscrição dos professores, começamos a analisar as fichas tentando traçar um perfil da sua formação. À medida que os encontros

PINTO, Vera L. X. et al. Educação permanente de professores: a reflexão-ação na promoção da alimentação saudável nas escolas. Extensão em Foco, Curitiba: Editora da UFPR, nr.10, jul/dez 2014, p.37-58. ISSN 2358-7180. 
aconteciam, os materiais eram arquivados, sendo manipulados posteriormente ao encerramento dos encontros. Foi primeiramente realizada uma leitura de tudo o que foi produzido e dos relatos feitos pelos professores.

b) Exploração do material: essa fase caracteriza-se pela escolha das unidades de análise, bem como enumeração e classificação dos dados em categorias. Depois da leitura inicial, foi confeccionada uma tabela, na qual as práticas pedagógicas desenvolvidas pelos professores nas escolas foram relacionadas. O material produzido durante o curso foi então separado por um professor, em ordem cronológica, sendo observadas as diferenças na expressão do conhecimento sobre alimentação saudável e a inserção de práticas alimentares diferentes daquelas enunciadas no início do curso.

c) Tratamento dos dados, inferência e interpretação: fase em que se pretende dar significância aos dados, a partir da produção de quadros, gráficos, diagramas e figuras que objetivem o destaque das informações obtidas, ou elaboração de textos reflexivos. Foram comparados relatos (escritos e orais), realizados pelos professores no início e no final do curso, bem como da análise de suas fichas de inscrição no que diz respeito à formação de cada um.

\section{Resultados e discussão}

Foi observado que, dos professores inscritos no curso e que participaram da pesquisa, 38,46\% possuíam formação superior em Pedagogia e 23,08\% estavam cursando essa carreira. 15,38\% concluíram o Ensino médio com formação em Magistério e 23,08\% haviam terminado o Ensino médio regular, ou seja, a maioria, ou $76,92 \%$ eram professores que haviam escolhido essa profissão desde sua formação.

Não foi observada nenhuma distinção nas práticas adotadas antes ou após o curso quando se usou como parâmetro a formação acadêmica do professor.

Tal fato sugere pensar que, para trabalhar com a PASE, o nível de formação acadêmica não é o fator mais relevante, e sim o acesso à educação permanente. $O$ contato com ideias, práticas e informações que ilustrem o valor de promover a alimentação saudável, permite aos professores inseri-las em sua atuação no universo escolar quando são motivados a isso.

O importante nesse processo foi a constatação de que a mudança foi um elemento presente no discurso e na prática dos professores, em suas vidas 
particulares e profissionais, oriundas da adoção de um processo reflexivo como guia de suas ações. Foram destacadas as categorias reflexão-ação na alimentação e reflexão-ação na prática pedagógica como elementos significativos para a discussão.

\section{Reflexão-ação na alimentação: o pensamento sem fronteiras.}

Para promover alimentação saudável é importante compreender o caráter social da alimentação, ou seja, ter em vista que, para além da reposição de nutrientes, as práticas alimentares englobam "o que se planta, o que se compra, o que se come, como se come, onde se come, com quem se come, em que frequência, em que horário, em que combinação, tudo isso conjugado como parte integrante das práticas sociais." (ROTENBERG E VARGAS, 2004, p. 86).

Realizar práticas alimentares consonantes com a construção de um corpo e de uma mente sã requer conhecimento sobre o que é melhor em cada momento da vida, condições de aquisição dos produtos desejados e capacidade de interagir socialmente para fazer da ingestão de alimentos um momento de trocas afetivas, de conversações agradáveis, de interação e pertencimento.

A escola, no passado, pouco influenciou na construção do comportamento alimentar. Nutricionistas (PINTO, 2006) e professores (PINTO et. al, 2010), relatam a fragilidade do trabalho dessa instituição no tocante a essa temática.

O avanço das DCNT torna urgente a mudança de tal realidade, e a portaria 1010, ao estimular a PASE, trata a formação e as ações pedagógicas sobre o tema com tanta relevância quanto os diagnósticos nutricionais e a garantia da qualidade dos alimentos servidos nesse espaço.

Pelo que foi observado na reserva, quando os professores entram em contato com tais temas pela via da formação reflexiva, passam a abordá-los com frequência, de maneira que o aluno compreenda a alimentação não apenas como ato biológico, mas também social e preponderante para uma boa qualidade de vida e desenvolvimento de um adulto saudável.

Um fato importante a ser destacado nesse processo, ademais, foi a adoção de práticas alimentares saudáveis em suas vidas, em suas famílias. Aprender é tornar a ação discurso. Apoiar os professores a pensarem sobre suas práticas alimentares levou-os à reflexão e à mudança.

PINTO, Vera L. X. et al. Educação permanente de professores: a reflexão-ação na promoção da alimentação saudável nas escolas. Extensão em Foco, Curitiba: Editora da UFPR, nr.10, jul/dez 2014, p.37-58. ISSN 2358-7180. 
Muitas ações que não promoviam saúde foram relatadas e, pelo simples fato de provocar essa reflexividade em relação ao comer, o curso de formação apareceu como uma linha divisória entre a construção desta distinção entre alimentarse e nutrir-se.

Grande parte dos professores falou sobre algum tipo de equívoco alimentar, seja relacionado a conceitos, composição, armazenamento ou conservação de alimentos, mas o caráter recorrente nos discursos foi a tomada de consciência que gerou a mudança de hábitos. Berger e Luckmann (1985) nos chamam a atenção para o complexo trabalho que significa mudar um hábito.

Atuar sempre da mesma forma nos alivia da tensão que a variação provoca, logo, mudar algo que se pratica ao longo da vida requer um desejo de refletir sobre o que foi feito, o que se faz agora e o que se poderia fazer. Ou seja: adotar o pensamento reflexivo como norteador das ações. Como disse Perrenoud (2002, p.17), "todos refletimos para agir, durante e depois da ação, sem que essa reflexão gere aprendizagens de forma automática. Repetimos os mesmos erros, evidenciamos a mesma cegueira, porque nos falta lucidez, coragem e método".

Nota-se que oportunizar cursos de formação que desencadeiem um processo reflexivo é de suma importância para a PASE. "O processo de formação não pode ocorrer de fora para dentro, pois conhecimento é uma procura, algo incompleto e incessante." (PINTO; 2006 p.126).

Essa procura pelo conhecimento leva à formação de uma consciência (auto)crítica, a qual proporciona mudanças no comportamento do indivíduo, que culminará na adoção de práticas que objetivem melhorias na qualidade de vida, caracterizando um autocuidado.

Embora o curso fosse sobre como promover a alimentação saudável nas escolas junto a crianças e adolescentes, o professor, sendo estimulado à reflexividade pelas atividades propostas, foi capaz de voltar-se para si e refletir sobre a saúde do adulto: “[...] a gente se preocupa mais até com a gente mesmo, como adulto [...]." (Rita Baiana).

Repensar sua alimentação e estilo de vida foi um passo também significativo e inevitável: "[...] antes desse curso eu achava que tudo era certo e podia, que 
futuramente não me prejudicaria, mas hoje vejo de outra forma [...] antes eu procurava o que era mais fácil e prático." (Inocência).

A aquisição de novos conhecimentos aliada ao processo reflexivo levou à adoção de novas práticas. A clareza da distinção que há entre alimento e nutriente e a necessidade de conjugá-los em uma alimentação saudável foi explicitada por Carolina: "O que eu estou me alimentando mais é fruta, feijão, muito ferro, muito cálcio".

Este "muito" de sua fala pode levar à preocupação com uma supervalorização dos nutrientes, uma desmesura comum em uma prática alimentar cientificista, que pode desconsiderar as leis da quantidade e harmonia e valorar a ingestão de algum nutriente específico considerado promotor de saúde, vigor etc., sendo a desmitificação da ideia de ser vantajoso o excesso de um elemento isolado -mesmo sendo ele importante para o corpo- um dos cuidados que se deve ter ao trabalhar na PASE.

A professora em questão, contudo, segue seu discurso, demonstrando a aprendizagem de outros princípios nutricionais importantes, como a adequação e a qualidade, evidenciando a aquisição de uma concepção ampliada de alimentação saudável: "[...] o que o curso me fez ver diferente foi a importância dos alimentos na nossa vida. Porque fruta é importante, carne é importante... Tudo! Mas sempre tem que ter o momento certo para aquele alimento. Um prato colorido".

É relevante destacar aqui a importância da formação para a criação de novas formas de pensar e agir, uma vez que a "postura reflexiva e o habitus correspondente a ela não se constroem de forma espontânea" (PERRENOUD, 2002, p.44), mas podem ser trabalhados.

Os relatos dessas mudanças foram mais evidentes e significativos porque envolveram processos práticos que culminaram em resultados perceptíveis, como revelaram os participantes do curso quando expressaram uma relevante transformação em suas práticas alimentares, evidenciando sempre muita alegria pelas modificações que promoveram em suas vidas e na de seus familiares.

"No seio familiar [...] os integrantes [...] compartilham sabores que são traduzidos em momentos de prazer, de harmonia, de dedicação, de aprendizagem cotidiana." (PINTO, 2006, p. 173). Ao refletirem sobre as práticas alimentares, sobre

PINTO, Vera L. X. et al. Educação permanente de professores: a reflexão-ação na promoção da alimentação saudável nas escolas. Extensão em Foco, Curitiba: Editora da UFPR, nr.10, jul/dez 2014, p.37-58. ISSN 2358-7180. 
a complementação que deve existir entre o alimentar e o nutrir, os professores paulatinamente foram mudando suas atitudes alimentares.

Como a necessidade de transmitir conhecimentos é algo universal, que faz parte da natureza humana - pois como diz Freire (1996, p. 58) "[...] não foi a educação que fez mulheres e homens educáveis, mas a consciência de sua inconclusão é que gerou a educabilidade" -, algumas vezes essa mudança era fruto de uma capacidade de unir os ensinamentos dados pela mãe com aqueles adquiridos durante o curso.

Por estar centrado na reflexão e não no mero repasse de informações - ou educação bancária, como nominou Freire (2004) -, o curso promoveu a capacidade de tomar decisões, de agir mediante uma atitude refletida, como nos mostra Macabéa: "muitas coisas eu passei a fazer ou a comer que antes eu não comia".

Tampouco a professora afirma que a mudança é algo fácil de realizar "eu me lembro que mãe dizia que eu só tomava se fosse leite moça. Agora não, com muita dificuldade já consigo tomar um pouco do outro leite".

Também é fácil perceber em suas palavras a importância do indivíduo empenhado em modificar seus hábitos ter clareza que se trata de um processo, em que as coisas vão sendo modificadas paulatinamente, e que cada progresso realizado é ganho global no processo de autocuidado: "como feijão todo dia, que antes não era desse jeito".

Cabe ainda comentar a importância do apoio àqueles que desejam enfrentar o desafio da mudança, pois um arcabouço conceitual, ou mesmo a volição, mostraramse suficientes para o domínio sobre si, para o aumento do repertório alimentar: "só as frutas que ainda precisa o empurrão da minha mãe para eu comer".

A cozinha, segundo Giard (1996, p. 259), é um lugar privilegiado "de uma doce intimidade, conversas sem nexo travadas a meias palavras com a mãe que vai e volta da mesa para a pia e da pia para o fogão, com as mãos ocupadas mas o espírito disponível e a palavra atenta a explicar, discutir, reconfortar".

Os professores inscritos no curso de formação desejaram estender aquele conhecimento, que paulatinamente construíam, aos familiares, promovendo alterações em seus hábitos alimentares: "na minha casa está sendo uma experiência bem gratificante, mudei toda nossa alimentação." (Inocência).

Claro está que a mãe é uma figura muito importante na construção do

PINTO, Vera L. X. et al. Educação permanente de professores: a reflexão-ação na promoção da alimentação saudável nas escolas. Extensão em Foco, Curitiba: Editora da UFPR, nr.10, jul/dez 2014, p.37-58. ISSN 2358-7180. 
comportamento alimentar. Ao afirmar "estou comendo bastante frutas, que antes eu comia pouco. Verduras também eu como", Rita baiana, sem perceber, cria um enlace com outras afirmações feitas por ela, como a de que seus filhos "só querem comer sanduíche, não gostam de frutas e tudo".

Pesquisas como as de Campbell e Crawford (2001) e Scaglioni e Galimberti (2008) mostram o importante papel da família nas decisões dos filhos, mesmo frente à publicidade. Não é por acaso que sua nova prática passa a refletir também na de seus filhos: "eles já estão começando a adquirir o hábito de utilizar esses alimentos vegetais, estão se preocupando também com alimentação".

Mas não é somente no seu núcleo familiar imediato que, segundo os professores, reverberaram as reflexões provocadas pelo curso. Branca Dias aproveita o tema como mote de conversação com a mãe "Quando eu estou lá na casa da minha mãe eu converso com ela também sobre o curso e fico conversando sobre as coisas que eu estou aprendendo aqui".

Inocência também nos mostra que o assunto parece interessar às pessoas de sua família e que a efetivação da mudança também é viável: "Sempre que viajo procuro passar para os meus familiares, eles estão sempre me perguntando se tenho novidades [...] já consegui mudar várias coisas, e vou continuar tentando mudar".

O aspecto financeiro, proporcionando uma redução de gastos com alimentação, também foi destacado. No Brasil, a alimentação é um item de grande peso no orçamento familiar. Comer saudavelmente, ao contrário do que se pensa, pode implicar uma significativa redução nesse percentual: "[...] até uma coisa que eu estava dizendo a Cirino [o marido] mês passado, ele dizendo: 'o que houve que minha feira baixou?' Porque diminuí um monte de coisa: biscoito recheado, todinho. Eu tirei tudo!".

"Educar no campo da nutrição implica criar novos sentidos e significados para o ato de comer" (BOOG, 2004). Na perspectiva de que o professor desempenhe um papel fundamental na construção de hábitos alimentares saudáveis na criança e no adolescente, o desenvolvimento de uma proposta de formação que evidencie esse enlace da educação com a nutrição, baseada na reflexão, é de fundamental importância.

PINTO, Vera L. X. et al. Educação permanente de professores: a reflexão-ação na promoção da alimentação saudável nas escolas. Extensão em Foco, Curitiba: Editora da UFPR, nr.10, jul/dez 2014, p.37-58. ISSN 2358-7180. 
As transformações individuais, advindas da inserção em um processo reflexivo, repercutiram de forma positiva nas práticas alimentares dos familiares, o que é considerado um ganho significativo nesse curso. Professores ressignificaram ensinamentos antigos e puderam difundir novas ideias, promover modificações para além dos muros das escolas, pois o pensamento não conhece fronteiras.

\section{Reflexão-ação na prática pedagógica: uma ideia bem nutrida}

A abordagem de temas como "Alimentação e Nutrição" é uma tarefa difícil e delicada, pois, além de buscar maior interesse por parte do aluno, o professor, em alguns casos, precisa romper com conceitos e preconceitos já presentes na identidade do aluno, bem como é necessário preservar a cultura e respeitar os padrões financeiros de cada um.

A alimentação se diferencia também, dependendo da idade, do estado de saúde e da situação social. Em todas as idades encontramos prescrições e proibições conforme representações e significado dos alimentos. Assim, não existe somente uma diferenciação por idade, como também a alimentação constitui uma variável importante na diferenciação entre pobres e ricos (ROTENBERG; VARGAS, 2004, p. 86).

Dessa forma, fica evidente a necessidade de adoção de práticas pedagógicas que envolvam o tema e sejam capazes de despertar o interesse e a curiosidade das crianças, levando-as à aquisição de um novo conceito de alimentação saudável. Foi relevante observar o que disse uma das participantes do curso em relação à sua filha, que esteve presente em um dos encontros no qual o tema discutido foi "arrumação de geladeira", para o qual foi utilizada como recurso didático uma geladeira construída em cartolina.

Eu tenho minha filha de 8 anos que assistiu a aula de vocês, ela foi para casa na minha frente e quando eu cheguei ela tinha feito uma geladeira de uma caixa e papelão igual a de vocês. [...] quando eu cheguei, ela já estava arrumando a geladeira, o que tinha errado ela já tinha ajeitado tudo. Ela não deixa a irmã dela mais velha colocar as coisas erradas. (Inocência)

O professor além de criar novos hábitos alimentares, pode também modificar os já existentes, utilizando-se de práticas e métodos que priorizem tal objetivo.

PINTO, Vera L. X. et al. Educação permanente de professores: a reflexão-ação na promoção da alimentação saudável nas escolas. Extensão em Foco, Curitiba: Editora da UFPR, nr.10, jul/dez 2014, p.37-58. ISSN 2358-7180. 
Segundo Bizzo e Leder (2005), a construção da Educação Nutricional deve ser feita de maneira integrada, entre conceitos, atividades e vivências da criança, e não dissociado das práticas exclusivamente teóricas. É interessante que o professor procure buscar o lúdico, envolva-se na prática e passe-a com prazer ao aluno, como realizado por Macabéa: "[...] no meu trabalho, eu também acho que a transformação foi grande, porque no que eu passo a gostar, então tenho mais prazer em passar aquilo para o meu aluno".

O curso de formação provocou os professores à realização de mudanças nas práticas e metodologias relacionadas à alimentação e nutrição. Os professores eram estimulados e a cada novo encontro contavam suas experiências.

Houve modificações em vários aspectos. A forma de consumir os alimentos foi uma delas. Os lanches passaram a ser vistos de forma diferenciada pelos professores, como nos conta Macabéa: "[...] a gente começou a trabalhar assim: dois dias na semana o lanche não são eles que trazem, nós da escola é que fazemos. [...] a transformação foi imensa".

Para esses professores, esse momento não se reduzia à questão puramente nutricional, mas era visto como um ato social, inserido em um contexto cultural. Percebiam que comer no ambiente escolar poderia e deveria ter função pedagógica.

O que mudou na prática pedagógica na minha vida depois do curso
"Em Torno da Mesa" foi justamente sobre a alimentação. [...]
ultimamente eles estão procurando trazer algumas frutas. [...] eu falei
para eles que não tivessem vergonha de trazer, porque é melhor
comer uma comida saudável do que pipoca, pirulito, que isso não irá
fazer bem. (Branca Dias)

Certos estavam de que "[...] o comer não satisfaz apenas a necessidade biológica, mas preenche também funções simbólicas e sociais." (RAMALHO; SAUNDERS, 2000, p. 12). Flora afirma: "pude rever muitas coisas, e adotar na minha sala de aula algumas atividades que as professoras fazem aqui conosco [...] a autobiografia alimentar que eu realizei com alunos maiores e que foi muito bom!".

A autobiografia alimentar (PINTO, 2006) foi inserida no curso como um elemento motivador da reflexividade. Sua utilização como metodologia parte da ideia de que o indivíduo é uma (re)apropriação do universo social e histórico que o rodeia, e que sua história individual o reflete.

PINTO, Vera L. X. et al. Educação permanente de professores: a reflexão-ação na promoção da alimentação saudável nas escolas. Extensão em Foco, Curitiba: Editora da UFPR, nr.10, jul/dez 2014, p.37-58. ISSN 2358-7180. 
Ao escrever ou narrar os eventos que constituíram sua existência, o sujeito comporta-se ao mesmo tempo como ator e autor de sua própria vida, sendo capaz de modificar as representações que tem de si e do mundo que habita. Esse processo (auto)formador engendra um movimento de transformação/reconstrução de si, que se inicia com a narrativa de sua história (PASSEGGI, 2000).

Os professores foram convidados, durante o curso, a realizar a autobiografia de sua formação, incluindo o aspecto alimentar. Os momentos de compartilhamento destas lembranças foram rodeados de emotividade e ficaram "tatuados" na memória de muitos deles, de tal forma que, ao final do curso, aqueles momentos ainda eram referidos como os mais significativos.

Isto foi de fundamental importância para nós pesquisadores, pois a utilização do método autobiográfico foi uma escolha consciente de que este é um método capaz de promover o que Morin (2003) chama de reforma do pensamento, visto que valoriza a compreensão que se desenvolve no interior da pessoa a partir das vivências experimentadas ao longo da vida. No dizer de Gaulejac (1998) "é uma forma de ajudar alguém a compreender em que ele é um produto da história e de mudar seu relacionamento com a história, num trabalho de restauração, que vai beneficiá-lo".

Segundo Lispector (1999), o homem, para entender o futuro, precisa ter tido um passado. As pessoas que contam suas histórias podem construir e reconstruir sua identidade pessoal por meio da relação com a sociedade. Como nos lembra Miguel (2004), a sociedade muda e a pessoa que vai refletindo sobre si torna-se capaz de observar-se dentro de uma estrutura social que se transforma.

As vivências relacionadas às autobiografias alimentares promoveram momentos intensos durante o curso, nos quais os professores puderam, a partir das histórias individuais, entender a história da comunidade, encontrar paralelos entre as vivências de suas infâncias com as das crianças que agora educam, permitindo a esse retorno o encontro de um caminho à compreensão, ao amor.

O motivo da professora usar esse mesmo recurso pedagógico com seus alunos faz pensar o quanto é importante promover sensações ao educar, pois ela afirma: "[...] o momento mais importante do curso foi a autobiografia, por isso que eu senti a necessidade e a vontade de também passar essa sensação para os meninos, meus alunos." (Flora)

PINTO, Vera L. X. et al. Educação permanente de professores: a reflexão-ação na promoção da alimentação saudável nas escolas. Extensão em Foco, Curitiba: Editora da UFPR, nr.10, jul/dez 2014, p.37-58. ISSN 2358-7180. 
A transmissão exige, evidentemente, competência, mas também requer, além de uma técnica, uma arte. Exige [...] o eros, que é, a um só tempo, desejo, prazer e amor; desejo e prazer de transmitir, amor pelo conhecimento e amor pelos alunos. O eros permite dominar a fruição ligada ao poder, em benefício da fruição ligada à doação. É isso que, antes de tudo mais, pode despertar o desejo, o prazer e o amor no aluno e no estudante. (MORIN, 2003, p. 102)

Esse processo de aproximação com o eros proporcionou uma preocupação de cunho holístico ao educar. O curso sempre se iniciava com uma atividade corporal visando trazer as pessoas para o momento, desenvolver a concentração e promover a reflexão sobre a necessidade da junção entre corpo e mente.

Durante todo o curso, atividades intelectivas e corporais foram conjugadas. A roda rítmica envolvendo todo o grupo e "acordando" os corpos para as atividades foram sempre realizadas no início dos encontros. Aos poucos, aqueles que antes se mostravam surpreendidos e entusiasmados com esta vivência que Ihes parecia exótica foram integrando estas duas instâncias do seu ser e observando o quanto era importante tal atividade para educar o ser humano de forma totalizadora. A cada encontro, os professores se mostravam mais integrados e traziam relatos de como a roda rítmica encantava seus alunos, que pediam constantemente a sua realização.

A "roda rítmica" e brincadeiras como o "capitão mandou", que consistiam em um convite ao movimento sincronizado com o outro, indiretamente, mostravam o quanto a escola descuida do corpo, superdimensionando atividades intelectuais. Branca Dias inseriu essas atividades em suas aulas e fala das vantagens observadas:

tenho observado o que funciona na formação da roda rítmica e do capitão mandou. [...]. Eles interagem bem, se concentram, procuram ter agilidade em fazer cada movimento corporal, têm a preocupação em não errar para não deixar de participar e observo que tentam ser cooperativos.(Branca Dias)

Os Parâmetros Curriculares Nacionais consideram que é papel preponderante da escola propiciar o domínio dos recursos capazes de levar à discussão de temas transversais como o cuidado com o próprio corpo e a saúde, valorizando e adotando hábitos saudáveis como um dos aspectos básicos da qualidade de vida e agindo com responsabilidade em relação à saúde e à saúde coletiva (BRASIL, 2004). Realizar atividades lúdicas, nas quais o corpo é destacado em seus movimentos - ritmo, leveza,

PINTO, Vera L. X. et al. Educação permanente de professores: a reflexão-ação na promoção da alimentação saudável nas escolas. Extensão em Foco, Curitiba: Editora da UFPR, nr.10, jul/dez 2014, p.37-58. ISSN 2358-7180. 
coordenação - pode se transformar numa oportunidade de desenvolvimento da autopercepção, e sem dúvida, a capacidade de observar o próprio corpo em todos os seus aspectos é o primeiro passo para o autocuidado, que diretamente produz mais saúde.

O checklist utilizado para obter uma panorâmica sobre as condições físicas das cozinhas escolares e das práticas higiênico sanitárias oportunizou aos professores os relatos de suas observações. Estes falaram da diferenciação do paladar das refeições produzidas em uma mesma escola nos turnos diferentes, em função do zelo maior de determinadas merendeiras, o que afeta, segundo eles, a ingestão dos alimentos pelas crianças, que relatam a diferença de paladar quando porventura há uma troca de turnos pelas cozinheiras.

Neste momento, discutiram amplamente o papel dos professores na divulgação da alimentação saudável e sobre as possibilidades do fazer pedagógico reverberar em toda escola este anseio em difundir bons hábitos alimentares, para os escolares e seus familiares. Muitas angústias foram partilhadas neste momento, pois os professores relataram a falta de controle dos pais sobre os filhos em inúmeras questões, dentre elas, as escolhas alimentares. Foi reforçada pelo grupo a necessidade de se fortalecer o vínculo entre família e escola e o envolvimento dos pais em projetos pedagógicos que enalteçam a alimentação saudável.

A ação do docente no incentivo a práticas saudáveis é imprescindível, uma vez que "a intervenção do professor tem, pois, um papel central na trajetória dos indivíduos que passam pela escola" (OLIVEIRA, 2000 p. 15). E, vale salientar que, os professores têm uma forte influência sobre as atitudes dos alunos por seu contato expressivo e envolvimento tanto na escola como em ambientes sociais.

Segundo Davanço et. al., (2004), todo professor exposto a curso de formação atribui a si a função de estimular hábitos alimentares saudáveis. Isso foi claramente percebido no discurso dos professores: "[...] esse curso mudou muito o nosso dia a dia com os alunos na sala de aula". (Inocência).

O professor, além de criar novos hábitos alimentares, pode também modificar os já existentes, utilizando-se de práticas e métodos que priorizem tal objetivo. "O professor é o membro central da equipe de saúde escolar, pois, além de ter maior

PINTO, Vera L. X. et al. Educação permanente de professores: a reflexão-ação na promoção da alimentação saudável nas escolas. Extensão em Foco, Curitiba: Editora da UFPR, nr.10, jul/dez 2014, p.37-58. ISSN 2358-7180. 
contato com os alunos, está envolvido na realidade social e cultural de cada discente e possui uma similaridade comunicativa". (DAVANÇO et al., 2004, p.179).

A Portaria Interministerial № 1.010 propõe a incorporação do tema alimentação e nutrição no contexto escolar, com ênfase na alimentação saudável e na promoção da saúde, reconhecendo a escola como um espaço propício à formação de hábitos saudáveis e à construção da cidadania.

Se Assinelli (2005 p.26) está correto ao afirmar que "a Educação alimentar é essencial para que a criança se torne um adulto feliz!", e que as "crianças não fazem o que mandamos; elas copiam o que fazemos!", parece-nos essencial trabalhar a (auto)formação de professores, pela via do pensamento reflexivo, o que pode ajudálos a tornarem-se o espelho que faria bem a toda criança mirar.

\section{Considerações finais}

A realização desse curso proporcionou aos professores a aquisição de novos conhecimentos em relação à alimentação saudável, propiciando mudanças em suas práticas alimentares, que, por sua vez, foram estendidas, em alguns casos, a familiares e amigos, acarretando alterações em suas vidas pessoal e profissional.

O curso despertou nos professores o desejo de incluir em suas práticas pedagógicas o conceito de alimentação saudável, permitindo às crianças e adolescentes uma aproximação com essa ideia.

Como desdobramento desta atividade ficou a reflexão sobre a importância de trabalhar também com outros profissionais da comunidade escolar, como coordenadores, supervisores e diretores - que segundo relatos dos professores não davam ao tema a importância merecida por falta de conhecimento -, e com a família, primeiro grupo ao qual a criança pertence e que incide decisivamente nas suas escolhas alimentares, tornando-se algumas vezes impermeável ao apoio que a escola pode (e deve) dar a seus filhos para a adoção de escolhas mais saudáveis.

Para concluir, é importante destacar que a verdadeira força que assegura um trabalho pedagógico de qualidade vem do próprio professor, regido pela vontade, arte, fé e amor. Acreditar nisso faz pensar no quanto afetiva e efetivamente se faz a condução de um trabalho como o que foi realizado.

PINTO, Vera L. X. et al. Educação permanente de professores: a reflexão-ação na promoção da alimentação saudável nas escolas. Extensão em Foco, Curitiba: Editora da UFPR, nr.10, jul/dez 2014, p.37-58. ISSN 2358-7180. 
O maior ganho foi vivenciar momentos significativos com um grupo que se mostrou envolvido e comprometido com a promoção da educação voltada para a saúde pelas dimensões do corpo (movimentos, jogos, ritmos), intelecto (cognição, conteúdos) e alma (arte, poesia) com vistas à promoção da autonomia, e que evidenciou a reflexão-ação como um via importante para a formação de professores para o trabalho de PASE.

\section{Referências}

ALARCÃO, I. (Org). Formação Reflexiva de Professores: Estratégias de supervisão. Portugal: Porto Editora, 1996.

ASSINELLI, Máximo. O mundo mudou a comida também. Curitiba: GGS Gráfica e Editora, 2005.104p.

BARDIN, Laurence. Análise do conteúdo. Lisboa: Edições 7, 1977.

BIZZO, Maria Letícia Galuzzi; LEDER, Lídia. Educação nutricional nos parâmetros curriculares nacionais para o ensino fundamental. Revista de Nutrição, Campinas, v. 18, n. 5, p. 661-667, set./out. 2005.

BOOG, Maria Cristina Faber. Educação Nutricional: por que e pra quê? Jornal da Unicamp. 02 de agosto de 2004. Disponível em: $<$ http://www.scielo.br/scielo.php?pid=S1519-38292004000100008\&script=sci_ arttext>. Acesso em: 17/11/2011.

BRASIL. Análise da estratégia global para alimentação saudável, atividade física e saúde. Brasília: Ministério da Saúde, 2004a. Disponível em: $<$ http://iah.iec.pa.gov.br/iah/fulltext/pc/portal/ess/v14n1/pdf/v14n1a05.pdf >. Acesso em 06/06/2011.

Ministério da Educação. Secretaria de Educação Básica. Departamento de Políticas Educacionais. Parâmetros Curriculares Nacionais: Saúde. Brasília: Ministério da Educação, 2004b.

. Portaria Interministerial 1.010, de 08 de maio de 2006. Institui as Diretrizes para a Promoção de Alimentação saudável nas Escolas de Educação Infantil, Fundamental e Nível Médio das redes públicas e privadas, em âmbito nacional. Diário Oficial da União, Brasília, DF, 09 maio 2006. Disponível em: <http://dtr2001.saude.gov.br/sas/PORTARIAS/Port2006/GM/GM-1010.html>. Acesso em 08/03/2011.

CABELLO, Maria Josefa Martínez. Educación Permanente y Educación Social: controversias y compromisos. Málaga: Ediciones Aljibe, 2002.

CAMPBELL, K.; CRAWFORD, D. Family food environments as determinants of preschool-aged children's eating behaviours: implications for obesity prevention policy. A review. Australian Journal of Nutrition and Dietetics, v. 58, n. 1, p. 19-25, 2001.

PINTO, Vera L. X. et al. Educação permanente de professores: a reflexão-ação na promoção da alimentação saudável nas escolas. Extensão em Foco, Curitiba: Editora da UFPR, nr.10, jul/dez 2014, p.37-58. ISSN 2358-7180. 
DAVANÇO,Giovana Mochi; TADEI, José Augusto Carrazedo; GAGLIANONE, Cristina Pereira. Conhecimentos, atitudes e práticas de professores de ciclo básico, expostos e não expostos a Curso de Educação Nutricional. Revista de Nutrição, Campinas, v. 18, n. 5, p. 177-184, abr./jun. 2004.

FREIRE, Paulo. Pedagogia da autonomia: saberes necessários à prática educativa. 30. ed. São Paulo: Paz e Terra, 1996.

Pedagogia do oprimido. 39. ed. Rio de Janeiro: Paz e Terra, 2004.

GAULEJAC, Vicent de. Conferência. Trabalho apresentado no Seminário de Sociologia e Psicanálise. Natal (UFRN), 1998 (Anotações especiais).

GIARD, Luce. Cozinhar. In: CERTAU, Michel; GIARD, Luce; MAYOL, Pierre. A Invenção do cotidiano - [2 morar e cozinhar]. Petrópolis: Vozes,1996.

GONÇALVES, Fernanda Denardin; CATRIB, Ana Maria Fontenele; VIEIRA, Neiva Francenely Cunha; VIEIRA, Luiza Jane Eyre de Souza. A promoção da saúde na educação infantil. Interface - Comunicação Saúde Educação, v.12, n. 24, p. 181-92, jan./mar. 2008.

LISPECTOR, Clarice. A descoberta do mundo. Rio de Janeiro: Rocco, 1999. 478p.

MIGUEL, Jesús M. de. La memória perdida. Revista de Antropología Social, Madri, v. 13, p. 9-35, 2004.

MORIN, Edgar. A cabeça bem-feita: Repensar a reforma, reformar o pensamento. 8. ed. Rio de Janeiro: Bertrand Brasil, 2003. 128p.

. Os sete saberes necessários à Educação do Futuro. 6. ed. São Paulo: Cortez; BRASILIA, DF: Unesco, 2002.

OLIVEIRA, M. K. O pensamento de Vygotsky como fonte de reflexão sobre a educação. Cadernos Cedes, 2. ed., ano XX, n. 35, p. 15, jul. 2000.

PASSEGGI, Maria da Conceição. A dimensão histórica do sujeito na formação docente. In: CONGRESSO BRASILEIRO DE HISTÓRIA DA EDUCAÇÃO, 2. Anais... Publicação eletrônica, 2002.

PERRENOUD, Philippe. A prática reflexiva no ofício do professor: Profissionalização e Razão Pedagógica. Porto Alegre: Artmed, 2002.

PINTO, Vera Lúcia Xavier. As coisas estão no (meu) mundo, só que eu preciso aprender: autobiografia, reflexividade, e formação em Educação Nutricional. 2006. 279 f. Tese (Doutorado em Educação Nutricional) - Centro de Ciências Sociais Aplicadas, Universidade Federal do Rio Grande do Norte, Natal, 2006.

PINTO, Vera Lúcia Xavier et al. (Org.). É de pequeno que se aprende? Promoção da alimentação saudável na Educação Infantil. Natal: EDUFRN, 2006. p. 57-76.

RAMALHO, Rejane Andréa; SAUNDERS Cláudia. O PAPEL DA EDUCAÇÃO NUTRICIONAL NO COMBATE ÀS CARÊNCIAS NUTRICIONAIS. Revista de Nutrição. Campinas, v. 13, n. 1, p. 11-16, jan./abr. 2000.

PINTO, Vera L. X. et al. Educação permanente de professores: a reflexão-ação na promoção da alimentação saudável nas escolas. Extensão em Foco, Curitiba: Editora da UFPR, nr.10, jul/dez 2014, p.37-58. ISSN 2358-7180. 
ROTENBERG, Sheila; VARGAS, Sonia de. Práticas alimentares e o cuidado da saúde: da alimentação da criança à alimentação da família. Rev. Bras. Saúde Materno Infantil. Recife, v. 4, n. 1, p. 85-94, jan./mar. 2004.

SCAGLIONI, S.; GALIMBERTI, M. Influence of parental attitudes in the development of children eating behavior. British Journal of Nutrition, 99, supl. 1, p. 22-25, 2008. 